\title{
AN ARCHETYPE OF A NATIONAL HEALTH SECURITY LEARNING NETWORK
}

\author{
Ade G. Ola, Virginia State University, aola@vsu.edu \\ Emmanuel E. Omojokun, Virginia State University, eomojokun@vsu.edu \\ Adeyemi A. Adekoya, Virginia State University, aadeyemi@vsu.edu \\ Xue Bai, Virginia State University, xbai@vsu.edu
}

\begin{abstract}
The United States' health security strategy has been designed to achieve two main goals of strengthening and sustaining the health and emergency response systems and building community resilience. The objectives deemeed necessary to achieve the goals include the establishment of non-pharmaceutical countermeasures that may be needed to mitigate the damage caused by a health incident and maintenance of continuity of communications through technologies that facilitate communication without person-to-person contact. This paper presents a model of a learning network for health security to allow continuity of $K-12$ instruction in the event of a health incident that warrants extended closure of schools. The learning network could serve as the primary tool for keeping students from congregating at one location in order to break the cycle of infection. The network will enable States and school districts to transition seamlessly from the classroom setting to a virtual collaboration and learning environment where the quality of instruction and learning is maintained. It will provide tools to depict the classroom environment by supporting the usual classroom teaching and learning strategies. The network has the potential for becoming a significant piece in each State's arsenal of security and emergency preparedness tools.
\end{abstract}

Keywords: Emergency Planning, Health Security, Continuity of Operations, Incident Response System, LMS, Collaboration and Learning Tools, Open Architecture and Framework

\section{INTRODUCTION}

The United States National Health Security Strategy (NHSS) [20] defines national health security as a state in which the Nation and its people are prepared for, protected from, and resilient in the face of health threats or incidents with potentially negative health consequences. NHSS also refers to "health incident" as a wide range of natural and man-made phenomena that may have health consequences, including, but not limited to, infectious disease outbreaks, hurricanes, earthquakes, storms, tornadoes, tsunamis, hazardous material spills, nuclear accidents, biological and other terrorist attacks, and fires. Primarily, NHSS is aimed specifically at the goals of protecting people's health in the case of an emergency or health incident. It establishes the mutually dependent relationship between national security, homeland security, and national health security-it affirms that the health of the citizenry has a direct impact on the nation's security. This paper focuses on non-pharmaceutical countermeasures that may be needed to mitigate damage from a health incident and to support continuity of communications in K-12 environment. The research is in response to specific calls by several U.S. government agencies for enhanced capabilities relating to health security in the school environment. More specicically, it will attempt to:

- Provide Continuity of Communications so that workplace risk can be minimized through implementation of systems and technologies that facilitate communication without person-to-person contact [3]

- Plan for Pandemic Severity Index Category 5 (a severe pandemic) in which prolonged implementation of community mitigation measures that could impact workforce absenteeism such as school closure for up to 12 weeks is required [4]

- Implement layered interventions at the community level, including dismissal of students from school with social distancing of children, and social distancing at work and in the community [5] 


\section{Issues in Information Systems}

Volume 13, Issue 2, pp. 260-268, 2012

- Develop State, regional, and local school district continuity of operations plans to ensure academic continuity for all students affected by a disaster [10]

- Ensure continuity of learning using a variety of technologies to facilitate one-on-one interaction between students and teachers, counselors and other appointed adults (e.g., tutors) during prolonged absences or dismissals and conducting live class meetings with tools such as conference calling or webinars, online courses, or virtual schools with two-way interaction between the teacher and students [21]

- Provide immediate resources to reopen and restore the learning environment in a timely manner and provide support for displaced students and their host schools [11]

- Initiate community mitigation activities such as school dismissal and childcare closures, social distancing, and the efficient management of public health resources [1]

This paper presents a model of a learning network for health security so as to allow continuity of K-12 instruction in the event of a health incident that warrants extended closure of schools. The learning network could serve as the primary tool for keeping students from congregating at one location in order to break the cycle of infection in the event of a pandemic or similar crisis. The network would enable States and school districts to transition seamlessly from the classroom setting to a virtual collaboration and learning environment where the quality of instruction and learning is maintained. It will provide tools to depict the classroom environment by supporting the usual classroom teaching and learning strategies and permitting students to engage in the learning process and maintain constructive contact with peers. From any location with Internet access, without any special software, the students would be able to engage in the learning process under the direction of their respective teachers. The network, when fully implemented at the local level, has the potential for becoming a significant piece in each State's arsenal of security and emergency preparedness tools.

\section{IMPLEMENTATION OBJECTIVES}

In order to deliver the capabilities relating to health security in the school environment, the following implementation objectives are required:

- Providing a robust virtual learning environment so that K-12 instruction is not disrupted in case of a disaster or an epidemic that prevents physical classroom meetings

- Providing the capability to transition seamlessly from the classroom to a virtual learning environment even when the school district's premises and technology infrastructures are inaccessible

- Implementing strategies and procedures to ensure that the emergency learning environment is sustainable so as to perpetuate its lifespan and guarantee its usefulness

- Providing effective collaboration and learning tools to depict the classroom environment by supporting the usual classroom teaching and learning strategies and permitting the students to engage in the learning process and maintain constructive contact with peers

- Provisioning adequate network capacity to meet bandwidth requirement for the population to be served

\section{Implementation Approach for Objective Category 1}

The objective is to provide a robust virtual learning environment so that K-12 instruction is not disrupted in case of a disaster or an epidemic that prevents classroom meetings. To provide a robust and stable virtual learning infrastructure, a solution and implementation approach has been devised by asking this question: How should an organization put together an effective learning infrastructure that supports a wide range of learning requirements, that has the ability to integrate with other administrative and academic systems, that can be built systematically (allowing components to be added, updated and replaced without destabilizing the overall environment), and that 


\section{Issues in Information Systems}

Volume 13, Issue 2, pp. 260-268, 2012

adapts to new technologies over time? The question is really a description of the challenge that had been posed by higher education leaders in their quest for cost-effective and robust collaboration and learning technologiestechnologies that support a wide range of learning best practices and yet robust enough to endure in the face of technological changes. In response to the challenge, the Open Knowledge Initiative $\mathrm{T}^{\mathrm{TM}}(\mathrm{OKI})$ - an organization dedicated to open collaboration and learning environment - has defined an architecture (i.e., framework) for how software components can be assembled to meet these requirements and other needs of the higher education community. The proposed solution approach for this project is based on the OKI Framework and other open standards and technologies related to learning systems.

OKI has defined an open and extensible architecture for learning technologies; it provides detailed specifications for interfaces among components of a learning management environment and offers open source examples of how the interfaces work. The architecture is being used both by commercial product vendors and by the open source community to provide a stable, scalable base that supports the variety of learning requirements. As a result, there are various enabling technologies that are flexible enough to adapt to a wide range of instructional requirements and styles and yet stable enough to allow teachers and students to concentrate on teaching and learning and not on the technologies. The expected result of this project is a robust and stable collaboration and learning environment that will always be available for any school district that seeks to maintain continuity of instruction in pandemic and other emergencies that warrants extended closure of schools.

\section{Implementation Approach for Objective Category 2}

This objective calls for the capability that will allow for a seamless transition from the classroom to a virtual learning environment even when the school district's premises and its technology infrastructures are inaccessible. The learning network, which will be distributed and located apart from the infrastructures for the school districts, will maintain curriculum and learning resources as well as up-to-date student data that are required to switch promptly from the classroom to the virtual learning environment. Central to the capability to transition seamlessly to the virtual environment is the effective data transfer between the proposed learning infrastructures and the school districts' information technology systems. Thus, the project seeks to implement data link capability to allow automatic transfer of student information bi-directionally between the emergency learning network and information systems at the school districts. The data transfer mechanisms and devices to be implemented will be based on interoperability standards, which will enable the various information systems being employed at the district level to be handled. The project will provide middleware tools that take advantage of the Schools Interoperability Framework (SIF). SIF, a data sharing open specification for K-12 schools, is an industry initiative that enables diverse applications to interact and share data. The industry-supported technical blueprint ensures that the diverse instructional and administrative software applications will work seamlessly together over time, and school districts have been acquiring software that are based on the framework.

Training materials for the teachers would include scripts and usage modeling, so as not to place undue burden on them. Periodic test runs will be prescribed to ensure smooth transition to the online learning environment during emergencies. Furthermore, school districts would be encouraged to take advantage of the emergency learning infrastructure to provide homebound instruction. Currently, local school divisions expend portions of their budget on acquiring the services of roving teachers that provide one-on-one homebound instruction for students who, for one reason or the other, cannot attend school. Making use of the health security learning network intermittently for other purposes would enhance familiarity with the network and enhance emergency preparedness.

\section{Implementation Approach for Objective Category 3}

This objective calls for implementation of strategies and procedures to ensure that the health security learning network is sustainable so as to perpetuate its lifespan and guarantee its usefulness. The learning network will be based on the OKI framework to ensure its sustainability. The architecture will allow new components to be plugged into the learning infrastructure using standardized application programming interfaces; this will allow the project 


\section{Issues in Information Systems}

Volume 13, Issue 2, pp. 260-268, 2012

team to take advantage more easily of novel technologies and new learning management components as they become available. In addition, intentionally, the network will be built to take advantage of the expertise and the infrastructures at select universities in the States. Higher education leaders have long recognized that learning systems are core components of their information technology infrastructures. Thus, the university community has been the driving force behind the OKI framework and the subsequent open source development efforts. Besides, in the past few years, universities and colleges have been adopting rapidly various mature open source learning systems and tools. Universities and colleges, as the major adopters of OKI based learning systems, possess considerable expertise which will be employed in sustaining the network.

The universities and colleges are also suitable host sites because of their stable network infrastructures. In an emergency, a number of universities are in the position to apportion appropriate bandwidth to meet the requirements of the learning network. Moreover, many of the universities are members of the Internet 2 community, which is actively engaged in developing and deploying emerging network technologies critical to the future of the Internet. Internet2 members leverage their high-performance network and worldwide partnerships to support and enhance their educational and research missions. The Internet2 Network, through its regional network and connector members, connects over 60,000 U.S. educational, research, government and other institutions, including primary and secondary schools. The network will rely heavily on Internet 2 capabilities.

\section{Implementation Approach for Objective Category 4}

The objective calls for the implementation of effective collaboration and learning tools to depict the classroom environment by supporting the usual classroom teaching and learning strategies and permitting the students to engage in the learning process and maintain constructive contact with peers. To be an effective alternative to the classroom, the emergency learning network must allow the usual classroom activities to continue unabated. Thus, the proposed learning network will provide tools that will facilitate the implementation of learning and teaching best practices such as engaging students, performing continuous and frequent assessment of student learning, and incorporating small group activities. The benefit of using the OKI framework as the base infrastructure is that it provides interfaces that support educational services in class administration, content repository, assessment, and communication services. Tools will be provided to accommodate a wide range of instructional requirements and styles. Acquired tools will conform to IMS Tools Interoperability (TI) Guidelines, which provides a framework that allows tools to integrate easily into OKI collaboration and learning environment. With the IMS TI guidelines, external tools may be attached side-by-side with the native learning tools of a central learning system.

Without requiring any special equipment, the learning network will permit multi-party collaboration and support audio/video conferencing and ink input, with shared canvas; it will provide the capability to record learning sessions, which students can play back at a later time. To support the usual classroom teaching and learning strategies, the features of the learning network will include:

- Allowing teachers to download/upload class materials for students

- Permitting students and parents to download course materials

- $\quad$ Providing internal e-mail support

- $\quad$ Providing students with file storage areas

- Allowing online exam/test creation by teachers

- $\quad$ Providing the capability for the teacher to schedule an exam or test for a specific date and time and set time limits

- $\quad$ Providing the capability for students to be organized into study groups and to meet online

\section{HEALTH SECURITY LEARNING NETWORK}

There is a variety of learning management systems, both as open source and proprietary software, which can be implemented as the base system for a Health Security Learning Network. Also, there are increasing numbers of e- 


\section{Issues in Information Systems}

Volume 13, Issue 2, pp. 260-268, 2012

learning tools, including web 2.0 tools that are not specifically developed for educational purposes. Thus, given the rate of change in the sphere of e-learning related software, committing to a particular platform or a set of integrated products would hamper the sustainability of the Network. Developing new integration plug-ins and connectors to accommodate new tools and changes is a monumental task that could limit the effectiveness and sustainability of the network.

Rather than developing a product, the learning network is based on the OKI Framework. OKI, the Advanced Distributed Learning (ADL), the IMS Global Learning Consortium (IMS), and various committees of the World Wide Web Consortium (W3C) represent the leading organizations concerned with open standards and technologies for collaboration and learning. OKI has defined an open and extensible architecture for learning technology. ADL is the custodian of the Sharable Content Object Reference Model (SCORM) [13, 14, and 15]—a technical framework for fostering creation of reusable learning content through a harmonized set of guidelines, specifications and standards - while IMS oversees the development of interoperability specifications for learning technologies. The learning network is based on the following open standards and technologies.

\section{The OKI Framework}

Software architecture is a framework that defines an organization of system components. The OKI architecture is based on the approach that specifies what services are needed and how software components can reference and provide or use those services - without any reference to the specific technologies used to implement a service. The approach (of organizing systems around services) is referred to as Service-Oriented Architecture (SOA). The OKI architecture is based on service descriptions (referred to as Open Service Interface Definitions (OSIDs)), which are intended to be consistent, well beyond the life-time of the specific technology used to implement the services. Applications that acquire a service do so through the OSIDs, which should not change when a new version of the service is installed. The OSIDs service definitions insulate the applications making use of the services so the service provider can easily be switched. From the perspective of an educational institution, OKI's Service-Oriented Architecture provides an open and extensible framework that enables acquisition of a robust learning environment. The implementation architecture can be depicted as functional boxes fitted together to form a learning system in such a way that there are few dependencies. The architecture allows a system to be easily reconfigured to add or remove tools. Figure 1 taken from the Campus Project [17] illustrates the architecture; it shows two Learning Management Systems - Sakai [19] and Moodle [18] - along with their respective sets of native tools and the external tools, which are connected via the OKI bus and the respective gateways.

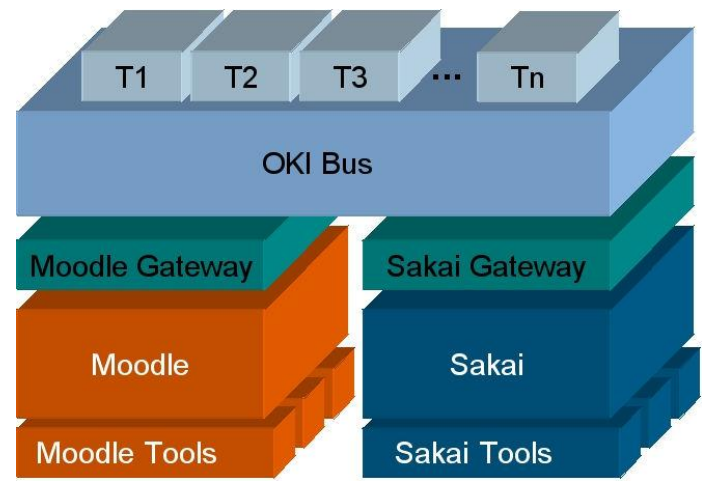

Figure 1: Diagram of the layers and components 


\section{Issues in Information Systems}

Volume 13, Issue 2, pp. 260-268, 2012

\section{Sakai: A Collaboration and Learning Environment}

Sakai Collaboration \& Learning Environment (CLE) is an open and extensible framework which provides basic capabilities to support a wide range of tools and services. The Sakai Project is a community source software development effort to design, build and deploy a collaboration and learning environment for higher education. The Sakai framework is suitable for use as a learning management system and small-group collaboration system. The core generic collaboration tools of Sakai include Site Setup, Repository Search, Schedule, Search, Announcements, Drop Box, and Email Archive. Some of the teaching tools provided are Assignments, Grade book, Section Management, and Syllabus. Sakai also provides a set of tools that implements the IMS Question \& Test Interoperability (QTI) [6] specifications. The QTI specifications describe a data model for representing questions and tests data and the corresponding results in reports. The specifications facilitate the exchange of question, test, and results data between authoring tools, question banks, test constructional tools, learning systems, and assessment delivery systems. The QTI tools make it easier to obtain and analyze feedback from students in the classroom or online; QTI Tools may also be used to produce guided notes.

\section{Open Tools for Implementing Small-group Learning Strategies}

An OKI-based CLE such as Sakai should be the base infrastructure for implementing small-group learning strategies for online education because most of the techniques require group collaboration and management. In addition to the central CLE, acquired tools should conform to IMS Tools Interoperability Guidelines (IMS TI) [8]. TI provides a framework that allows tools to easily integrate into a CLE; this enables the learning management system to present the external tools side-by-side with its native learning tools. The following consists of recommendations for facilitating various group activities:

A1: Forming cohesive groups

- Assessment of academic skills (using QTI tools)

- Survey information to determine interests and preferences of the learners (QTI tools)

A2: Modeling interaction and team-building skills

- Providing demonstrations to show interaction, discussion, and roles using recording facility of OKI-based CLE and IMS TI conferencing tools

- Providing interaction scripts or models in multimedia formats (using SCORM content)

A3: Monitoring interaction among learners in groups

- The instructor or the teaching assistant may participate in or moderate virtual meetings (using IMS TI conferencing or Ink applications)

- Inspecting the log of group discussions

- Monitoring interaction from recorded sessions of IMS TI meeting tools

A4: Designing learning resources for tutorials

- Simulation of classroom instructor-led lectures using dynamic handwritten notes and audio narration

- Recording class sessions for after-class review

- Providing captioning for lectures tailored to students with disabilities using Timed Text [23] instead of audio devices

\section{BANDWIDTH USAGE PLANNING}

One of the crucial aspects of implementing the health security learning network is the provisioning of adequate bandwidth to handle selected applications and the number of participants. 


\section{Issues in Information Systems}

Volume 13, Issue 2, pp. 260-268, 2012

Table 1: Bitrates per connection types

\begin{tabular}{|l|c|l|}
\hline $\begin{array}{l}\text { Student } \\
\text { Connection Type }\end{array}$ & $\begin{array}{l}\text { Bitrate } \\
\text { (Kbps) }\end{array}$ & Comments (codec and bitrates) \\
\hline $\begin{array}{l}\text { Web Conferencing } \\
\text { (Audio/Visual) }\end{array}$ & 320 & $\begin{array}{l}\text { BigBlueButton webcam at 320x240 or 640x480 both use same amount of } \\
\text { bandwidth of approximately 240-400 Kbps per stream. Let us assume 320 } \\
\text { Kbps on average (320Kbits/s). For N clients, the server handles NxN } \\
\text { downloads and uploads }\end{array}$ \\
\hline $\begin{array}{l}\text { 2-way audio } \\
\text { conference-1 speaker }\end{array}$ & 45 & $\begin{array}{l}\text { For audio, using RTP DVI at 8000, 11025 or 22050 Hz, 4 bits and 1 channel } \\
\text { (mono) / 11025Hz (Medium - 45Kbps) }\end{array}$ \\
\hline $\begin{array}{l}\text { 2-way audio } \\
\text { conference-2 speakers }\end{array}$ & 90 & Twice the bandwidth of single speaker \\
\hline $\begin{array}{l}\text { Screen Sharing } \\
\text { Whiteboard Broadcast }\end{array}$ & 64 & $\begin{array}{l}\text { Broadcast PowerPoint, edit documents collaboratively. Only the area of } \\
\text { screen which has changed is transmitted. Bitrate is up to 64Kbps }\end{array}$ \\
\hline Instant Messaging & 1 & Bitrate up to 64Kbps \\
\hline Movie-Casting & 256 & Bitrate dictated by video quality (assumes 256Kbps) \\
\hline Meeting Playback & 64 & Assumes same bitrate as the meeting without the 2-way audio. \\
\hline
\end{tabular}

The following connection types determine bandwidth requirements:

- Webcam 2-way (Audio/Visual) conferencing (codec, frame rate, and video size)

- 2-way audio conferencing (codec, frame rate, one/two speakers)

- Shared Desktop / Screen sharing

- Collaborative Whiteboard (broadcast meeting mode)

- Instant Messaging (Chat)

- Movie-casting

- Recorded meeting playback

Table 1 shows the approximate bitrates for the connection types.

Using the bitrates for the connection types, the bandwidth for each application or usage mode can be computed. For example, a lecture mode consisting of Audio, Whiteboarding and Instant Messaging requires 155Kbps $(90+64+1)$. Table 2 shows the bitrates for common learning applications or usage modes and number of participants.

Web conferencing is the dominant application. For example, handling 100 students requires $3.2 \mathrm{Gbps}$ server bandwidth. However, since the formula for calculating bandwidth is non-linear, 100 students in 5 concurrent classes each with 20 students will require less bandwidth (640Mbps). Having many smaller classes instead of one large class is recommended for another reason: intolerable delay is introduced when the server has to distribute the same data package to many clients, without multicast capability. However, the most likely application mode for student classes would be Audio/Whiteboard/Messaging or Audio/Shared Screen/Messaging which requires less bandwidth than 2-way web conferencing. Planning for the health security learning network must include provisioning of adequate bandwidth at each school district, for selected applications and the number of participants. 


\section{Issues in Information Systems}

Volume 13, Issue 2, pp. 260-268, 2012

Table 2: Bandwidth Requirement per Application or Usage Mode

\begin{tabular}{|c|c|c|c|c|c|c|c|}
\hline \multirow{2}{*}{$\begin{array}{l}\text { Application } \\
\text { /Use mode }\end{array}$} & \multicolumn{7}{|c|}{ Bandwidth (in Mbps ) / Number of Clients (N) } \\
\hline & 50 & 100 & 200 & 300 & 400 & 500 & Formula \\
\hline $\begin{array}{l}\text { Audio/ } \\
\text { Whiteboard/ } \\
\text { Messaging }\end{array}$ & 7.75 & 15.5 & 31 & 46.5 & 62 & 77.5 & $155^{*} \mathrm{~N}$ \\
\hline $\begin{array}{l}\text { Audio/ } \\
\text { Shared Screen } \\
\text { / } \\
\text { Messaging }\end{array}$ & 7.75 & 15.5 & 31 & 46.5 & 62 & 77.5 & $155^{*} \mathrm{~N}$ \\
\hline $\begin{array}{l}\text { 2-way A/V } \\
\text { Conference } \\
\text { (Webcam) }\end{array}$ & 1600 & 3200 & & & & & $320 * \mathrm{~N} * \mathrm{~N}$ \\
\hline $\begin{array}{l}\text { Audio/ } \\
\text { Whiteboard/ } \\
\text { Playback }\end{array}$ & 5.45 & 10.9 & 21.8 & 32.7 & 43.6 & 54.5 & $109 * \mathrm{~N}$ \\
\hline $\begin{array}{l}\text { Audio/ } \\
\text { Shared Screen/ } \\
\text { Playback }\end{array}$ & 5.45 & 10.9 & 21.8 & 32.7 & 43.6 & 54.5 & $109 * \mathrm{~N}$ \\
\hline $\begin{array}{l}\text { Movie- } \\
\text { Casting }\end{array}$ & 12.8 & 25.6 & 51.2 & 76.8 & 102.4 & 128 & $256 * \mathrm{~N}$ \\
\hline
\end{tabular}

\section{RELATED WORK AND CONCLUSIONS}

In an assessment report, the International Association for K-12 Online Learning has prescribed the application of online learning for emergency response [9]. The research work presented in this paper provides a model for implementing such a learning environment. There have been other eLearning projects based on the open and extensible architecture; but none, to our knowledge, is specifically for emergency response. Examples of eLearning projects based on open and extensible architecture include the CMU eLearning Architecture [2], the Open University Support System [22], and The SUN Microsystems e-Learning Framework [16]. A more recent and important work is the Campus Project [17]. Campus Project is middleware that supports integration of heterogeneous tools and applications (Java, PHP and others) into LMSs, such as Moodle (PHP) and Sakai (Java). The middleware tools use plug-ins to interact with a set of LMS services, independently of the LMS. Each LMS has a gateway that acts as a translator between the calls to the Campus Project services and the APIs of the different LMSs. The Campus Project demonstrates how to piece together into a heterogeneous system that has very few dependencies; with the architecture, it is easy to reconfigure and rearrange the system and change the constituent pieces.

This paper has put forth a model for health security learning network based on open technologies and standards. The learning network, when fully implemented, will allow continuity of K-12 instruction in the event of a health incident that warrants extended closure of schools. It will enable States and school districts to transition seamlessly from the classroom setting to a virtual collaboration and learning environment where the quality of instruction and learning is maintained. While implementation of the health security learning network has to necessarily take place at the local school division levels, a prototype implementation would serve as a guide for the States and local school authorities. The network has the potential for becoming a significant piece in the State's arsenal of security and emergency preparedness tools. 


\section{Issues in Information Systems}

Volume 13, Issue 2, pp. 260-268, 2012

\section{REFERENCES}

1. CDC (2007), Interim Pre-Pandemic Planning Guidance: Community Strategy for Pandemic Influenza Mitigation in the United States:.Ear/y. Targetcd, Use of Non-pharmaceutical interventions. February 2007

2. CMU eLearning Architecture http://www.lsal.cmu.edu/.

3. FEMA. Pandemic Influenza Continuity Annex Template Instructions, National Continuity Programs Directorate, Federal Emergency Management Agency, http://www.fema.gov/pdf/about/org/ncp/pandemic_influenza.pdf

4.FEMA. Key Elements of Departmental Pandemic Influenza Operational Plans

http://www.fema.gov/pdf/about/org/ncp/inf_key_elements.pdf

5.FLU: The Community Strategy for Pandemic Influenza (available at http: /.

www.pandemicflu.gov/plan/community/commitigation.html )

6. IMS Global Learning Consortium. 2006. IMS Tools Interoperability Guidelines, [online], Available:

http://www.imsglobal.org/ti/tiv1p0/imsti_guidev1p0.html

7. IMS Learning Design Specifications [online], Available: http://www.imsglobal.org/learningdesign/

index.html

8. IMS-QTI (2006) IMS Question \& Test Interoperability (QTI) specification, [online], Available:

http://www.imsglobal.org/question/index.html

9. iNACOL: International Association for K-12 Online Learning (iNACOL): Readiness Assessment.

http://www.inacol.org/col/docs/iNACOL_Readiness_Assessment_Questions.pdf

10. IRAA: IRAA School Emergency Preparedness

A Project of the Western Regional Homeland Security Advisory Council, June 2011.

http://westernmassready.org/iraa/docs/IRAA\%20Emergency\%20Preparedness\%20Resources_FINAL.pdf

11. Report to Congress: National Commission on Children and Disasters, Report to the President and Congress,

October 2010

http://cybercemetery.unt.edu/archive/nccd/20110427002908/http:/www.childrenanddisasters.acf.hhs.gov/index.html

12. Sakai Project. [online], Available: http://sakaiproject.org/

13. SCORM-CAM (2006) SCORM $20043^{\text {rd }}$ Edition Content Aggregation Model (CAM)

Version 1.0. Advanced Distributed Learning (ADL), November 2006

14. SCORM-SN (2006) SCORM 2004 3rd Edition Sequencing and Navigation (SN) Version 1.0

Advanced Distributed Learning (ADL), November 2006

15. SCORM-RTE (2006) SCORM 2004 3rd Edition Run-Time Environment (RTE) Version 1.0

Advanced Distributed Learning (ADL), November 2006

16. SUN: E-Learning Framework, SUN Microsystems Technical White Paper, SUN Microsystems, February 2003

17. The Campus Project, http://www.campusproject.org/en/index.php

18. The Moodle Project http://moodle.org/

19. The Sakai Project http://www.sakaiproject.org

20. United States HHS (2009). National Health Security Strategy of the United States of America, U.S. Department of Health and Human Services, December 2009

http://www.phe.gov/Preparedness/planning/authority/nhss/strategy/Documents/nhss-final.pdf

21. U.S. Department of Education; PREPARING FOR THE FLU: DEPARTMENT OF EDUCATION

RECOMMENDATIONS TO ENSURE THE CONTINUITY OF LEARNING FOR SCHOOLS (K- 12)

EXTENDED STUDENT ABSENCE OR SCHOOL DISMISSAL

http://www2.ed.gov/admins/lead/safety/emergencyplan/pandemic/guidance/continuity-recs.pdf

22. USSOPEN: the Open University Support System; http://www.openuss.org

23. Timed Text (2010): Timed Text Markup Language (TTML) 1.0, W3C Recommendation 18 November 2010,

http://www.w3.org/TR/ttaf1-dfxp/ 